\title{
A teoria da justiça de Rawls e a racionalidade retórica
}

\author{
Rawls' justice theory and rethorical rationality
}

Manuela Braga Fernandes*

Recebido em:10/2015

Aprovado em:11/2015

\begin{abstract}
Resumo: Rawls desenvolve a teoria da justiça por equidade a partir de fundamentos da metafísica, válidos e dedutíveis por todos. De acordo com essa teoria, a justiça, as leis e a decisão judicial são incontestáveis, pois advém de princípios universalmente válidos. No entanto, o procedimento judicial é de racionalidade retórica e, por natureza, trabalha com a dúvida, não há que se falar em necessidade, mas contingência. Da mesma forma, o realismo jurídico demonstra que a decisão judicial é eivada de subjetividade.

Palavras-chave: Teoria da justiça, racionalidade retórica, realismo jurídico.
\end{abstract}

Abstract: Rawls develops the theory of justice by equity from metaphysical fundaments, valiable and dedutible by everyone. According to this theory, justice, law and judicial decision are incontestable because they come from universally valid principles. However, the judicial procedure is one of rethorical rationality and, by nature, develops itself from doubt, there is no space for necessity, but only contingency. Legal realism, on its turn, also demonstrates that the judicial decision is penetrated by subjetivity.

Keywords: Justice theory, rethotical rationality, legal realism.

\section{Introdução}

A teoria da justiça de Rawls é desenvolvida a partir da posição original, um imperativo categórico que ajuda a

\footnotetext{
* Doutoranda do Programa de Pós-Graduação em Ciências Jurídicas da $U F P B$
}

Problemata: R. Intern. Fil. v.6, n. 3(2015), p 63-84 ISSN 2236-8612

doi:HTTP://dx.doi.org/10.7443/problemata.v6i3.26041 
compreender a análise moral dos princípios de justiça que devem reger a sociedade. Em razão da sua natureza de filosofia pura, ou metafísica, a ideia de Rawls é que justo e injusto, leis e decisões advindas de instituições sociais são universais, absolutamente válidas para todo.

Ele entende que esses parâmetros advêm de escolhas que todos os homens livres e iguais fariam dadas circunstâncias similares, portanto, são ideias válidas e dedutíveis por todos. Vestidos do véu da ignorância, pessoas livre e iguais definem os princípios da justiça que devem ter validade absoluta.

No entanto, os princípios da justiça são manipulados e possivelmente concretizados através do Judiciário. $\mathrm{O}$ procedimento judicial se dá através de racionalidade retórica, isto é, dialética. A decisão judicial é produto de discurso e parte de uma dúvida, por isso os resultados não podem ser demonstrados como na racionalidade apodítica. Assim, o discurso judicial se dá através de premissas contingentes e não necessárias. Dessa forma, os parâmetros de verdade e justiça absolutos de Rawls podem não se concretizar passados pelo teste da retórica judicial.

O realismo jurídico, por sua vez, ajuda a compreender o processo de formação da decisão judicial como algo incerto e subjetivo, negando a ideia de teoria da predição judicial, como compreende a tese rawlsiana. Para os realistas, a decisão depende de quem a profere e das circunstâncias que são apresentadas no processo pelas testemunhas e advogados.

Dessa forma, o trabalho parte da pergunta: os parâmetrosde justiça de Rawls podem sobreviver à analise do procedimento do judiciário para garantir a justiça? A resposta provisória dessa indagação é que não, a racionalidade processual é retórica e por isso contingente, depende de escolhas e preferencias que a metafisica não é capaz de admitir.

Para refletir acerca da pergunta inicial o trabalho se divide em três etapas. A princípio vai entender a posição original de Rawls e a ideia metafísica de justiça que surge a partir daí. Em seguida, compreende a racionalidade judicial de natureza retórica, e por isso, contrária àmetafísica. Por fim, demonstra a maneira realista de tomar o procedimento judicial de feitura da decisão para corroborar a retórica judicial como método contrário à metafisica. 


\section{A posição original para construção da teoria da justiça de Rawls}

A ideia de organização em sociedade de Rawlsé de uma cooperativa com intuito de obter vantagens mútuas, de modo que a vida em sociedade é mais vantajosa que viver dos seus próprios esforços individualmente. No entanto, com o aumento da produtividade resultante da colaboração o interesse individual vai no sentido de conseguir quinhões maiores da partilha. É necessário, então, um conjunto de princípios que determine como se dará a partilha, quais são os direitos e deveres ou os benefícios e encargos da cooperação social (RAWLS, 1981, p. 28). Esses princípios são os princípios da justiça social.

A ordem social vem da satisfação do conceito público de justiça. O conceito de justiça depende de duas medidas: que todos aceitem os mesmos princípios de justiça e que as instituições sociais satisfaçam a execução desses princípios (RAWLS, 1981, p. 29). Com isso, mesmo que os homens discordem entre si, concordam com parâmetros comuns a partir dos quais as demandas podem ser resolvidas. Dessa forma, embora os homens tenham tendência a agir de acordo com seus interesses, seu sentido comum de justiça torna possível conviver em associação segura.

No entanto, não apenas a coincidência no conceito de justiça é suficiente para a associação viável, é preciso também enfrentar as questões de coordenação, eficiência e estabilidade. As atividades humanas devem ser arranjadas de modo que sejam compatíveis entre si e que, em certo grau, contribuam para os objetivos sociais, isto é, sejam eficientes para a concretização dos princípios de justiça. Da mesma forma, entende Rawls, o esquema da sociedade deve ser estável. Estabilidade para ele é a manutenção de forças estabilizadoras diante do cometimento de violações, de modo a restaurar o consenso (RAWLS, 1981, p.29).

Compreende dizer, portanto, que a ordem vem da coordenação, da eficiência e da estabilidade. O que se toma, então, é que é necessário que os princípios de justiça estejam plenamente acordados para tomar como certo e definitivo o que vem a ser coordenado, eficiente e estável. A reflexão que esse trabalho busca trazer é se é mesmo possível definir parâmetros de justiça metafísicos dos quais a teoria de Rawls tanto depende. 
Ele mesmo, em certa medida, parece concordar com a dificuldade de ter a definição de justiça em caráter absoluto quando diz que "as sociedades atuais raramente estão em boa ordem neste sentido, sendo que o justo e o injusto estão em geral em discussão"(RAWLS, 1981, p.28). A partir disso, nos propomos a compreender a natureza dialética da sociedade, que não é capaz de definir absolutamente o justo e o injusto e quais as consequências disso para a teoria de Rawls.

Ele segue na construção da sua teoria de justiça advertindo que o sentido de justiça não pode ser meramente distributivo. Para Rawls cada pessoa tem uma inviolabilidade nos seus fundamentos da justiça que nem o bem estar social pode se sobrepor. Por essa razão, não existe justiça em negar direito individual com fundamento que essa negativa pode trazer benefício maior para a coletividade; o sacrifício de um não é justificado pelas vantagens de muitos. Assim, a sociedade justa é aquela que toma parâmetros iguais e estes não podem estar sujeitos a barganhas ou cálculos de interesse social (RAWLS, 1981, p.34). A verdade e a justiça, portanto, por serem as principais virtudes das ações humanas, devem respeitar padrões inalterados e não podem estar sujeitas a compromissos.

Rawls preocupa-se bastante, portanto, em definir bases sólidas para o conceito de justiça. Para ele, não deve existir espaço para negociação ou subjetividade quando se discute justiça em sociedade. Da mesma forma a verdade. Esta, para Rawls, como a justiça, deve atingir parâmetro de indubitabilidade. A relação de proximidade entre verdade e justiça para ele pode ser exemplificada quando diz que "justiça é a primeira virtude das instituições sociais, como a verdade o é para o pensamento" (RAWLS, 1981, p.27). Assim, da mesma forma que o pensamento deve ter como produto a verdade de natureza definitiva, as instituições sociais devem buscar a concretização da justiça em parâmetros indiscutíveis.

Para definir o conceito de justiça de maneira definitiva Rawls assume postura contratualista. No entanto, ao contrário dos contratualistas clássicos ele argumenta que o objetivo do acordo inicial não é formar a sociedade em si, mas definir os parâmetros de justiça social; o acordo define os princípios de justiça e as estruturas básicas que podem concretizar os princípios. Pessoas livres e racionais que estejam em situação de igualdade definem os termos da associação que se dispõem a fazer. Esses princípios definidos em situação de equiparação vão 
definir todos os futuros entendimentos e desentendimentos. Ele chama essa maneira de perceber os princípios da justiça de justiça por equidade (RAWLS, 1981, p.33).

Nesse momento, que ele chama de posição original, portanto, os homens livres, racionais e iguais, através de ação conjunta formulam os princípios de justiça, direitos e deveres e distribuem os benefícios sociais, bem como estabelecem como as contendas devem ser resolvidas e como será a carta fundamental da sociedade. Um grupo de indivíduos vai decidir de uma vez por todas o que é justo e injustobaseado nos seus próprios parâmetros do que é o bem.

As definições feitas na posição original são feitas a partir do pressuposto de que ninguém conhece qual sua posição na sociedade, qual sua classe ou suas capacidades naturais ou se a distribuição de bens tem lhe favorecido ou desfavorecido, não conhece nem mesmo suas propensões psicológicas ou políticas. A decisão dos princípios de justiça é feita, portanto, em total ignorância acerca das particularidades individuais (RAWLS, 1981, p.34). Dessa forma, garante-se que não será possível tirar vantagens durante o processo, se todos são absolutamente iguais, pois se são cegos acerca de si não é possível fazer escolha que favoreça sua posição particular. Por essa razão Rawls chama o conceito de justiça assim formulado de justiça por equidade, pois o acordo de definição dos princípios de justiça é um acordo equitativo.

A partir dos princípios definidos, os homens ainda na posição original podem construir a Constituição que vai inspirar todo o ordenamento jurídico para, em seguida, definir as instituições sociais que podem colocar os conceitos em prática. Assim, a sociedade é construída de forma que todos que fazem parte do sistema podem afirmar que estão vivendo sob os parâmetros que teriam eles próprios escolhidos se fossem livres e iguais (RAWLS, 1981, p.34). Assim, quando a justiça é aplicada pelas instituições Rawls compreende que todos os homens concordam com essa aplicação.

De fato, as instituições sociais e suas decisões e imposições são os próprios princípios da justiça e do direito. Por esse motivo, o direito é necessário e suas decisões são produto direto da justiça equitativa (RAWLS, 1981, p.118). Esse raciocínio eleva as decisões de direito a uma situação de objetivismo absoluto, pois contestar decisão de direito seria 
mesmo que contestar os próprios princípios de justiça definidos em situação de igualdade. Assim, a decisão judicial deve ser prontamente aceita por quem acredita na justiça como equidade.

A posição original deve ser interpretada de modo que em qualquer momento seja possível assumir os mesmos princípios de justiça como certos. Em outras palavras, os princípios devem ser indiscutíveis a qualquer momento, de modo que sempre os mesmos princípios seriam escolhidos, dadas as circunstancias. E que circunstâncias são essas? Rawls traz, então, o conceito do véu da ignorância. $O$ véu é a chave para entender a justiça equitativa (RAWLS, 1981, p.119). Vestindo o véu da ignorância todos seriam iguais porque seriam ignorantes acerca de suas próprias condições. Suas particularidades políticas, sociais e psicológicas desaparecem sob o véu e a partir dai as decisões são tomadas de maneira equitativa e as instituições e constituições que se formam trazem consigo a justiça definitiva e indiscutível.

O véu da ignorância transforma as pessoas em livres e iguais, de modo que, com essas características, elas possuem as duas faculdades morais que garantem equidade: senso de justiça, bem como a capacidade de agir a partir dele e a concepção do bem, de modo que compreenda o que é necessário para ter vida digna (RAWLS, 2003, p. 26).

A posição original de Rawls muito se assemelha ao estado de natureza do contratualismo clássico. Aquela, como esta, não é tomada como fato histórico ou condição primitiva da humanidade, mas situação hipotética que ajuda a construir o conceito de justiça.A teoria é sobre julgamentos morais manifestados considerando situação de equilíbrio reflexivo.

Para ajudá-lo a construir esses conceitos Rawls inspira-se em Kant e na sua metafísica moral. Kant compreende que todos os conceitos morais tem sua origem a priori na razão humana e por isso não podem ser abstraídos da experiência, pois esta é contingente. Por isso os princípios morais são supremos. Por isso o conhecimento moral, como produto da razão pura, é válido para todos os seres racionais e é universal, pois todos podem deduzi-lo. Assim, a racionalidade moral corresponde à filosofia pura, não à filosofia empírica. A filosofia pura que se circunscreve a objetos é a metafísica (KANT, 2008, p.54). Portanto, o que Kant defende é que a metafísica diz respeito à racionalidade moral válida para todos e dedutível por todos. 
A partir da razão, portanto, os seres racionais tem vontade. Vontade, diz Kant, não é nada mais que razão prática. A representação objetiva da vontade se dá através dos imperativos. Imperativos são, assim, fórmulas que exprimem a relação entre a razão objetiva e a vontade subjetiva do ser racional.

Para ele existem dois tipos de imperativos: o hipotético, que é instrumental, é meio para conseguir determinado fim, e o categórico. O imperativo categórico é aquele que representa a ação como objetivamente necessária por si mesma, sem relação com qualquer outra necessidade.O imperativo categórico é um comando que não tem qualquer contato com o mundo empírico (KANT, 2008, p.94).

A posição original de Rawls é um imperativo categórico, não é fato histórico ou descrição de momento anterior à civilização, é uma racionalidade moral metafísica, um princípio de comando absoluto que não pode ser alterado. Portanto, a posição original e os princípios da justiça equitativa de Rawls são um princípio formal da moral, absoluto e necessário e serve como fundamento da ação moral. A partir dessa construção moral metafísica Rawls age como se o fundamento dessa construção possaser levado como norma universal e válida para todos. Por isso, para ele o justo e o injusto têm parâmetros absolutos e indiscutíveis; as leis e a decisão judicial, por sua vez, devem ser respeitadas por todos, pois seu fundamento é fundamento valido e dedutível para qualquer um.

Compreende-se, portanto, porque para Rawls, além da justiça, também a verdade é virtude suprema (RAWLS, 1981, p. 27). Seu conceito de justiça depende de uma verdade abstrata, total e indiscutível, que é a definição dos princípios de justiça ainda na posição original.

Com isso, tem-se que para Rawls com a efetivação dos princípios de justiça, a cidadania vai estar completa (RAWLS, 1981, p. 93).A justiça como equidade avalia a concretização dos seus efeitos através do exercício da cidadania na sociedade. Cidadania é o modo de pertencimento dos indivíduos a uma comunidade reconhecida pelo Estado. É a condição de quem goza direitos civis, políticos e sociais, sendo todos igualmente exigíveis (SORTO, 2009, P. 97). Assim, os parâmetros de cidadania são atingidos, para Rawls, quando os princípios da justiça por equidade são concretizados. Portanto, a possível demonstração das dificuldades de concretização desse modelo 
exposto por ele implica também dificuldade de concretização da própria cidadania sob o paradigma do modelo.

Uma das principais dificuldades da teoria de justiça de Rawls, já apontada por Martha Nussbaum, é o caráter excludente da sua teoria contratualista. As pessoas se vestem do véu da ignorância, passam por todas as etapas da posição original e saem, então, cidadãos. Mas o objetivo desse pacto não é outro se não a vantagem mútua; a cooperação social se dá, para Rawls, não pelo sentimento de justiça ou de benevolência, mas porque é mais vantajoso estar associado (NUSSBAUM, 2013, p. 71). Assim, esse pacto, pensando na vantagem mútua, exclui deficientes físicos e mentais e animais, cortando do quinhão da justiça por equidade boa parte dos indivíduos na sociedade.

A ideia de justiça de Rawls, portanto, vem da percepção de que é possível vantagem econômica através de cooperação, ao invés de dominação. No entanto, Rawls toma o cuidado de dizer que no contrato, aqueles que vestem o véu da ignorância e definem os princípios de justiça e instituições sociais, são pessoas racionais. Assim, ele exclui não só animais, mas também deficientes que, em razão das suas particularidades, não tem a mesma produtividade no acordo de vantagem mútua.

O momento reservado para definir a proteção dos grupos excluídos é posterior na teoria de Rawls. Eles não são, portanto, contratantes e quando não há representatividade, há exclusão (NUSSBAUM, 2013, p. 21). Não podem definir os parâmetros da sociedade em que viverão, à medida que seus direitos são posteriores e derivativos. A razão disso é que sua produtividade econômica dificilmente supera os custos da inclusão plena. Assim, o acordo rawlsiano admite eventuais gastos públicos com políticas em favor dos economicamente desfavorecidos, mas não dos deficientes físicos e mentais (NUSSBAUM, 2013, p. 249).

Nesse sentido, os parâmetros de justiça de Rawls parecem trazer consigo viés político que este não admite. Ao perceber que a teoria é pensada para garantir vantagem econômica àqueles contratantes, isto é, pessoas racionais, o que exclui diversos nichos onerosos para o Estado dentro da sociedade, é possível questionar as razões políticas que podem esconder-se no discurso de justiça, leis e decisões válidas para todos e, por isso, incontestáveis. 
Portanto, alegar que a teoria de rawlsiana não se propõe a defender forma particular de governo ou sistema econômico, como defende Neiva Oliveira (OLIVEIRA, 2000, p. 116), parece superficial. O próprio Rawls percebe a natureza política da sua teoria posteriormente, o que o leva eventualmente a publicar alguns trabalhos em que tenta sanar seus defeitos transformando-a mais numa teoria do liberalismo político, isto é, em filosofia empírica, e menos em metafísica (RAWLS, 2003, p. 1-6). Independente de qualquer arrependimento, no entanto, a ideia da posição original mantem-se como um conceito construído e defendido pelo autor e não anula a pretensão do trabalho de testá-lo sob o viés da racionalidade retórica e realista do direito.

As decisões judiciais são prementemente o foco do presente trabalho. É possível compreender o procedimento judicial de que parte da legislação escrita e culmina na decisão judicial e defender que o produto do sistema é válido e dedutível para todos como defende Rawls? Além disso, a teoria que sustenta a concretização da cidadania a partir de princípios fixos e absolutos pode mesmo se sustentar na sociedade? A partir disso é possível entender como se dá o procedimento judicial, aquele responsável por dizer, afinal, o que é justo ou injusto e, com isso, verificar se os parâmetros de universalidade de Rawls podem resistir a essa compreensão.

\section{A racionalidade retórica na concretização dos princípios de justiça}

A racionalidade pode ser dividida em duas, a apodítica e a dialética. A razão apodítica é que pode ser demonstrada, pois parte de premissas necessárias, em que não existem dúvidas, mas apenas certezas. A racionalidade dialética, por sua vez, parte de um dubium e se desenvolve no discurso através de opiniões, proposições, escolhas e predisposições.

Assim, quando se fala em premissas necessárias, como na matemática, tem-se a racionalidade apodítica. No entanto, a racionalidade que trabalha com categorias questionáveis, faz proposições, usa do discurso e da dedução para formar opiniões ou crenças é a dialética, e Aristóteles chama esse método de tópico (ARISTOTELES, 2007, p.233). Tópico vem do grego 
topos, lugar, e quer dizer que algo vem daquele lugar. Dessa forma, tópica é a racionalidade das particularidades, do discurso que não é necessário, mas contingente.

Entre a racionalidade lógica passível de demonstração ea pura arbitrariedade existe o campo da razoabilidade. Assim, a tópica é a racionalidade da argumentação razoável ou provável. Não se trata de opinião ou crença, pois essas são arbitrárias, mas de eudoxia, ou boa opinião. Que significa boa opinião? Trata-se da opinião que pode convencer; aquela que, aceitas as premissas, torna-se razoável. Em certo momento Aristóteles argumenta que a maioria dos atos bem intencionados visa o bem; quase todos os homensacreditam que o bem provoca felicidade; a maior parte dos homens, portanto, buscam felicidade. Essa argumentação é tópica (ARISTOTELES, 2007, p.234). Ela parte de premissa não necessária, "os atos visam bem" e constrói proposições que culminam na eudoxia de que os homens buscam felicidade. Essa conclusão depende de deduções e de proposições para se sustentar, mas sustenta, ou convence o interlocutor, por serem razoáveis.

A persuasão pelo discurso, por fim, usa o raciocínio dedutivo para construir um argumento. Tenta demonstrar o que parece ser a verdade através do que pode ser objetivo e persuasivo em cada caso particular (ARISTOTELES, 2005, p. 97). É a manipulação eficiente dos argumentos de modo a encadear causas e efeitos que persuadam os ouvintes.

A verdade material, a verdade como expressão do real, só pode ser, portanto, metafisica. Verdade é propriedade das proposições, independente da opinião dos homens, os raciocínios analíticos são demonstrativos e impessoais. Esse não é o caso dos raciocínios dialéticos, o raciocínio dialético é feito de opiniões geralmente aceitas. O que é geralmente aceito é verossímil, mas não se deve confundir essa verossimilhança com probabilidade calculável. Verossimilhança divide características com a razoabilidade, não com a probabilidade (PERELMAN, 1993, p. 22).

Desde já é possível perceber, portanto, a dificuldade de admitir o conceito de justiça, leis e decisões absolutas, como trazido por Rawls, já que, como se verá adiante, a discussão judicial tem natureza dialética e retórica. A única maneira de haver verdade e justiça de maneira universal, ou efetivamente materiais, como termos metafísicos, seria transformando a argumentação judicial numa demonstração (transformando, 
assim, tópica em lógica). Para fazê-lo o orador teria que precisar os termos utilizados eliminando toda ambiguidade e, com isso, retirar do raciocínio múltiplas interpretações (PERELMAN, 1993, p. 73). A impossibilidade reside aí; não parece possível eliminar completamente múltiplas interpretações dentro da discussão judicial, especialmente se se tem partes com interesses diametralmente opostos.

Dessa forma, a retórica vai servir quem for capaz de formar silogismos e puder teorizar sobre virtudes e paixões. Nesses termos, Aristóteles ensina que a retórica é filha da dialética. O entimema, o argumento retórico em que uma premissa explícita induz uma segunda premissa, é um silogismo (ARISTOTELES, 2005, p. 98), uma argumentação lógica, herdando a retórica parte de sua tradição da dialética.

Nesse tipo de racionalidade tópica existe dúvida e a dúvida incita o diálogo, que eventualmente leva à boa opinião. Com a boa opinião é preciso perceber se o interlocutor concorda com o orador, se convence. Esse processo é diferente da lógica, em que se trabalha com o monólogo; a tópica, por sua vez,constrói-se com o diálogo.

Assim sendo, retórica é a faculdade de descobrir os meios de persuasão efetivos sobre qualquer questão dada. É a técnica e a arte de questionar e sustentar um argumento, defender-se ou acusar (ARISTOTELES, 2005, p. 89) usando da melhor forma possível para assim fazê-lo. Para Aristóteles, então, a retórica é a capacidade de descobrir o que é adequado a cada caso com o fim de persuadir.

Nem todas as provas de persuasão são próprias da arte da retórica. São provas inartísticas as que não são produzidas pelo homem, como testemunhos e confissões sob tortura ou documentos escritos. Provas artísticas são as que podem ser preparadas através de método pelos homens, as que advêm do raciocínio. Assim, é necessário utilizar as primeiras, mas inventar as segundas (ARISTOTELES, 2005, p. 96). As provas artísticas são, portanto, a expressão do uso da retórica (MEDEIROS, 2015, p. 131), que excede a descrição das provas inartísticas e as trabalham para construir a verdade que interessa ao orador.

São três espécies de provas de persuasão através do discurso. Pelo caráter moral do orador, pela maneira que se 
dispõe o ouvinte e pelo que o próprio discurso parece demonstrar, como ensina Aristóteles (2005, p. 96).

Persuade-se pelo caráter quando o orador deixa a impressão de ser digno de fé;quando o orador convence o público que está qualificado para falar sobre o assunto e sua autoridade serve como meio de convencimento dos argumentos. No entanto, para falar precisamente de retórica é preciso que a confiança no orador seja resultado do discurso e não em razão de opinião prévia acerca deste individuo (ARISTOTELES, 2005, p. 96). Assim, se o orador convence que tem autoridade para falar sobre o assunto, a nova autoridade conquistada ajudao a persuadir seus ouvintes.

A persuasão pela disposição dos ouvintes se dá quando estes são levados a sentir emoção por meio do discurso. A retórica aqui usa dos sentimentos de tristeza ou alegria, ódio ou amor para convencer de um argumento. A amplificação de um argumento ou uma história podem ser usados para evocar emoções da audiência (ARISTOTELES, 2005, p. 97). Assim, o orador deve julgar se usar das emoções da audiência é conveniente e eficaz para provar sua ideia.

O discurso oratório comporta três elementos: o orador, o assunto sobre o qual se fala e o ouvinte. O resultado do discurso refere-se ao ouvinte; ele que, ao final, vai se manifestar, vai se convencer ou não. Para melhor compreender como se comportam os ouvintes, Aristóteles dividiu em três gêneros os discursos retóricos: o deliberativo, judicial e epidíctico.

$\mathrm{Na}$ retórica deliberativa os oradores aconselham ou dissuadem acerca de eventos futuros. No gênero judicial a acusação e a defesa persuadem o juiz acerca de um evento passado. No epidíctico tem-se o elogio ou a censura no presente (ARISTOTELES, 2005, p. 104).

Assim, a retórica judicial é justamente a argumentação jurídica prevista no modelo de processo judicial dogmático. Advogados de acusação e defesa devem escolher a melhor forma de persuadir o juiz acerca de como ocorreu um evento no passado. A finalidade dessa retórica, afirma Aristóteles, é o justo e o injusto. Apesar de não ser algo deliberadamente planejado, o injusto é um resultado possível na retórica judicial, pois o direito é um mecanismo de institucionalização de interesses (KENNEDY, 2002, p 62).

Dessa forma, o propósito do orador é convencer o ouvinte. Como já mencionado, o convencimento não pode se dar através 
de demonstração, pois a racionalidade do discurso judicial não é lógica, mas tópica e dialética. Assim, usando o método retórico, o orador deve construir o seu discurso pensando no ouvinte. Retórica é discurso adaptado(PERELMAN, 1993, p. 41).A partir de premissa que se adapta ao auditório e preocupando-se com a elocução é possível criar disposição no auditório para aceitar a argumentação e para, efetivamente, convencer. Importante perceber, portanto, que a retórica não demonstra, ela convence, o que significa que uma ou outra tese pode ser bem sucedida, pois dependem do manejo do orador. Por isso Aristóteles avisa desde o início que a retórica não tem compromisso com a justiça e ambas, justiça e injustiça, podem ser produto dela.

A tópica e a retórica não pensam a partir do sistema, mas do problema. Dessa forma, não existe por parte dos advogados ou do magistrado compromisso com o sistema judiciário, politico ou social, como compreende a teoria da justiça de Rawls. A preocupação desses oradores, cada um em seu momento, é com o problema que têm diante de si, com o caso concreto. Assim, se o juiz acredita que o sistema legal não é suficiente para solucionar um problema, ele pode construir argumentação razoável usando outros recursos, pois, para a retórica, o sistema não está posto, ele é montado através do problema (VIEHWEG, 1979, p. 34). Esse raciocínio guarda diversas similaridades com a teoria do realismo jurídico, que pensa a solução de problemas judicias não necessariamente a partir da norma escrita, mas também através do magistrado.

Os princípios de justiça, como ensina Rawls, são concebidos por pessoas racionais e por isso a justiça pode ser definida em termos absolutos. Ele age como se a racionalidade individual sobre as questões de justiça fosse a racionalidade apodítica, demonstrável e necessária. Mas é essa mesmo a racionalidade da política, da ciência social, historia ou direito?Após o demonstrado até aqui, seguro dizer que não. A racionalidade do procedimento judicial é retórica e tópica, parte da dúvida e constrói argumentos e pressupostos a partir de consensos para convencer. Dessa forma, o procedimento judicial não é completamente alheio ao aceite de injustiças, como repudiado por Rawls.

A teoria da justiça de Rawls é metafísica, pois se propõe como definitiva, como válida e dedutível por todos em razão do imperativo categórico da posição original, que criaria escolha de 
princípios e instituições únicas para todos. No entanto, a análise da racionalidade do procedimento judicial mostra que não há que se falar em definição ou demonstração válida para todos. A decisão judicial parte de premissas, proposições e escolhas que inspiram determinado conhecimento. Essa verdade final do processo não pode se confundir com averdade material, ou expressão fiel da realidade, éverossimilhança, expressão do que é razoável. Dessa forma, a injustiça, tanto quanto a justiça,é produto da decisão de direito. Assim, os princípios de justiça, as leis e as instituições podem cometer injustiças, ao contrario do que defende Rawls.

Da mesma maneira, a concretização da cidadania em Rawls fica prejudicada uma vez negada a metafísica da teoria da justiça por equidade. Se a cidadania depende das garantias dos princípios da justiça definidos na posição original, e essas garantias, como defendido, não podem existir de maneira absoluta, a própria cidadania em Rawls também está prejudicada.

Tomando parâmetros de retórica para descrever o procedimento de determinação de sentença judicial, o realismo jurídico ajuda a compreender de maneira pontual a discussão retórica aqui trazida.

\section{A decisão judicial a partir do realismo jurídico e a negação do principio absoluto de justiça}

A teoria absoluta da justiça de Rawls fica prejudicada quando compreende a racionalidade retórica e sua limitação às particularidades do caso, de forma que é impossível reproduzir o discurso de maneira universal. O realismo jurídico, por sua vez, descreve o procedimento judicial a partir da perspectiva retórica e negando a metafísica da teoria da justiça rawlsiana.

Para Jerome Frank (1968, p. 69)o testemunho é uma atividade psicológica subjetiva que depende de condicionantes que não atentam necessariamente para a realidade fática. A percepção e a reprodução dos fatos que são determinantes para o resultado da ação judicial são condicionadas por fatores psicológicos. O direito trabalha, portanto, com relatos, não fatos.

Os fatores mencionados podem ser subconscientes ou conscientes e deliberados. Qualquer testemunha quando entrevistada pelo advogado pode supor qual a melhor resposta

Problemata: R. Intern. Fil. v.6, n. 3(2015), p 63-84 ISSN 2236-8612 
para provar a tese daquele litigante. Se a testemunha deseja que aquela parte seja bem sucedida no processo pode moldar sua história de acordo com seu interesse (FRANK, 1973, p. 86). Assim, tem-se que fatores de ordem subjetiva como interesse podem ajudar a definir os fatos e, com isso, o processo.

Qualquer ação ou depoimento de indivíduo é resposta a um estímulo exterior. Essa resposta é condicionada pelo estímulo posto. Assim, as reações não são fruto do acaso, fazendo com que as ações humanas sejam sempre direcionados pelo entorno (FREUD, 1976, p. 107).

Freud chama de complexo tudo aquilo que determina a reação de uma pessoa ao estímulo. Qualquer pequeno ato aparentemente gratuito é reação ao complexo. Brincar com um determinado objeto, a escolha aparentemente aleatória de números, um nome que vem a cabeça, nada é arbitrário, tudo vem a mente em razão do exercício de associação, uma reação ao complexo(FREUD, 1976, p. 108). Então a testemunha conhece o complexo e através dos estímulos dos inquisidores vai reagir revelando esse complexo.

Se se toma a posição do juiz, este conhece o complexo através dos documentos iniciais do processo e a partir de então forma conteúdo ideativo. Assim, o juiz já conhecendo o complexo lança estímulos para a testemunha para descobrir se a reação desta é compatível com aquele conhecimento anterior do magistrado (FREUD, 1976, p. 108). Os próprios estímulos, portanto, são pensados em função de confirmarem o complexo. E mais, o complexo a que servem é uma visão parcial do juiz. Frank analisou isso mais profundamente e tem essa questão da descoberta dos fatos como a etapa mais importante do processo.

Um litígio se inicia não porque A ou B discordam sobre a regra de direito a ser aplicada naquela situação, mas porque $A$ ou B divergem sobre os fatos ocorridos em determinada situação. Assim, o trabalho do juiz de $1^{\mathrm{a}}$ instância é determinar através da análise das provas o que aconteceu de fato. Dessa maneira, a verdade para o processo não é necessariamente a verdade real, mas o que foi admitido pelo magistrado como verdade (FRANK, 1968, p. 26), ou seja, não se pode falar em verdade como última palavra em sentido abstrato, mas em verossimilhança. A determinação da verdade passa pelo processo de estímulo, associação e reação descrito por Freud, sendo sujeito, dessa forma, à alterações e manipulações 
subjetivas. A retórica ensina exatamente como a manipulação do discurso da verdade se dá.

Frank garante ainda que os métodos pessoais usados pelos juízes para determinarem a interpretação das provas não podem ser sistematizados ou transformados em regras, pois são fatores subjetivos de percepção que, muitas vezes, nem mesmo os magistrados têm catalogados para si (FRANK, 1968, p. 42). Para saber como o sujeito apreendeu a informação é necessário entender como esse indivíduo pensa, mas isso é impossível(FRANK, 1968, p. 51). Além disso, existe o problema dos erros. As testemunhas (e até as provas técnicas e científicas) são passíveis de erros que condicionam a interpretação dos fatos, estabelecendo-os de maneira diferente do que viria a ser (FRANK, 1968, p. 43).

Nesses termos, para Frank seria impossível criar uma ciência de predição legal em razão da questão da determinação dos fatos. Uma ciência dessa natureza teria que ser específica do magistrado que profere a decisão, uma ciência do único que, em si, é uma contradição (FRANK, 1973, p. 190).

Percebe-se, então que,para Frank, a questão central no processo judicial é a determinação dos fatos. No entanto, se esses fatos dependem de uma série de condições de ordem psicológica para serem relatados ao magistrado e processados por esse juiz, há mesmo que se falar em previsibilidade? Para Frank não. A subjetividade é sinônimo de relatividade (FRANK, 1968, p. 64), e relatividade nega previsibilidade. A associação da verdade processual à questão da relatividade aproxima-a da racionalidade retórico e nega, com isso, a metafísica. Dessa forma, verdade e justiça são conceitos tópicos e não lógicos, como precípua Rawls.

Assim, a incerteza que cerca qualquer processo judicial vem da interpretação dos fatos desde a $1^{\text {a }}$ instância, que condiciona todo o resto do processo. O direito não se faz, então, com direito, mas com os fatos. No entanto, nas palavras de Frank, "facts are guesses", ou fatos são suposições, afastando, assim, a ideia de certeza dentro da ação judicial(FRANK, 1973, p. 14).

No entanto, seguindo os ensinamentos do também realista Oliver Wendel Holmes, Frank entende que a subjetividade e, com isso, a incerteza no direito não advém só das dificuldades de entender a verdade através dos relatos dos fatos. As próprias 
características pessoais dos julgadores também vão condicionar o processo decisional. É o que se trata a seguir.

Seguindo as ideias deixadas por Holmes, o direito é predição de uma possível reação do Estado em relação aconduta de um agente (HOLMES, 2006). A personificação do Estado nos casos concretos se dá na figura do magistrado, bem como a reação do Estado vai se dar em relação aos fatos tomados no processo ainda na primeira fase.

A teoria da predição é formulada através do estudo de todo material jurídico produzido. A produção jurídica que pode englobar jurisprudência, legislação, principiologia e doutrina é, assim, oráculo da lei. Os esforços legais são, dessa forma, no sentido de tornar as profecias mais precisas (HOLMES, 2006).

Para isso, fazem-se generalizações a partir do conjugado de leis e jurisprudência ou, no caso de Holmes, de precedentes, demonstrando que, geralmente, diante do fato $X$ tem-se $o$ resultado Y. Em seguida, num caso concreto, são levantados os fatos de natureza relevante para o direito, de modo que se tem um modelo que pode ser alocado numa das generalizações anteriormente preparadas (HOLMES, 2006). Assim, o trabalho legal é predizer que, se um homem fizer ou deixar de fazer algo, ele poderá ou não ser levado a responder por isso por uma corte.

As generalizações são reduzidas a um número finito de dogmas que servem para fundamentar as predições. Se um estudioso do direito quer conhecer esses dogmas e nada mais, de modo a predizer resultados, Holmes o chama de bad man. O goodman, por sua vez, encontra suas razões de conduta, seja fora ou dentro do direito, em sanções da consciência (HOLMES, 2006).

O direito é permeado por conceitos advindos da moral, de modo que numa discussão jurídica é possível passear levianamente entre domínios do direito e da moral. Conceitos como direitos subjetivos, dever, malícia, intenção, negligência quando transformados em meros dogmas pelo badman caem em falácia. Esses conceitos, por natureza, são questionáveis e tem seu sentido alterado de acordo com o discurso, nos moldes ensinados pela retórica.

Quando preocupa-se com as questões morais, isto é, se a lei corresponde ao desejo moral do homem, o goodman pode concluir muitas vezes que as decisões das cortes não correspondem a reflexões de foro subjetivo. Esse jurista se 
dedica a uma dedução de princípios e axiomas que vai além de meros dogmas para entender que seria resultado justo para o caso concreto. O badman, pelo contrário, não tem qualquer preocupação por reflexões dessa natureza, ele preocupa-se em entender se a corte está propensa a este ou aquele resultadoatravés de análise objetiva (HOLMES, 2006). O que Holmes defende, portanto, é que dar sentido metafísico, isto é, válido e dedutível aos conceitos de direito, é tratar o direito de maneira incorreta.

O trabalho do badman é predizer se determinada ação ocasionará reação punitiva do Estado. Essa predição é o direito. $\mathrm{O}$ direito é assim, previsão de reação $\mathrm{X}$ do Estado diante de conduto $\mathrm{Y}$ do agente.No entanto, Holmes alerta que quando se toma decisões do passado para buscar apoio para as previsões do comportamento judicial do futuro não é suficiente tomar parâmetros puramente lógicos(FRANK, 1968, p. 9). Tem-se desde já a importância de se estar diante de goodman, que vai se desprender dos dogmas absolutos para refletir acerca da moral da decisão. Mas não apenas isso. Para desvendar uma decisão judicial é preciso ir mais além, descobrindo o contexto econômico social e político em que se deu a sentença.

$\mathrm{O}$ que Holmes fala acerca das influências econômicas, sociais e politicas refletindo na decisão do magistrado, Frank concorda sem ressalvas(FRANK, 1968, p. 10). A sentença é, além de raciocínio lógico, tradução das vivências pessoais de um indivíduo. Os problemas sociais, econômicos ou políticos que aquele sujeito que profere a decisão sofreu ou deixar de sofrer são refletidos na ordem da corte que comanda.

Portanto, se o direito é predição de comportamento judicial, resulta imprescindível ter em conta os diversos fatores subjetivos, eminentemente psicológicos, que gravitam sobre a vontade do julgador. Seus preconceitos, sentimentos e pretensões, sejam conscientes ou inconscientes, determinam, juntamente com a legislação, a jurisprudência e as demais fontes do direito, a decisão judicial.

Frank toma essas observações de Holmes e conclui que se se propõe a prever o direito, o jurista teria que conhecer $o$ homem que vai preferir a decisão, o que significa estudar todas as suas características pessoais. Assim, a pesquisa de predição seria empírica, circunstanciada e socialmente localizada. As conclusões, portanto, teriam valor relativo e não absoluto(FRANK, 1968, p. 28). 
Dessa forma, se o direito é predição de um comportamento humano, é preciso levar em conta os fatores econômicos, sociais e políticos que atuam sobre esse comportamento. A lógica das decisões passadas e a legislação escrita não são os únicos condicionantes da decisão. Da mesma forma, as influências sociais, econômicas e políticas dos juízes também o são(FRANK, 1968, p. 12). Nas palavras de Frank, o estado da mente de um homem é tanto um fato quanto sua digestão(FRANK, 1973, p. 157).

Ampliando as reflexões de Holmes, Frank entende que o problema de se dispor a prever o direito é que não é suficiente tentar antecipar a interpretação dada a norma pelo juiz. A previsibilidade da sentença depende de aspectos psicológicos de ordem econômica, social e politica do homem, responsável pela decisão que condiciona a maneira que ele entende o processo. Da mesma forma, vencida essa dificuldade teria que se preocupar novamente com a abordagem dos fatos que esse sujeito entende como verdade. A percepção dos fatos é outra variável de ordem psicológica, como visto no anteriormente.

A sentença judicial é, no entanto, produto final de um procedimento que se inicia anteriormente. O direito é construído através da legislação. A legislação é uma série de declarações condicionadas a determinado fato de referência. Assim, se determinado fato aconteceu, o efeito jurídico que se segue é $X$. Essa consequência jurídica é estabelecida no caso concreto através da decisão judicial.

Para definir a decisão judicial é preciso cruzar a regra jurídica com os fatos apresentados. Assim, se tem a equação $\mathrm{R} x$ $\mathrm{F}=\mathrm{D}$, em que $\mathrm{R}$ é a regra de direito; $\mathrm{F}$ os fatos definidos como realidade no processo e $\mathrm{D}$ é a decisão final.

A maioria dos juristas quando fala em certeza no processo judicial se volta para o $\mathrm{R}$ da equação. $\mathrm{O}$ cuidado para a garantia de justiça está regularmente voltada para a lei. Se a lei é estável, dessa forma seria possível ter decisões estáveis e previsíveis.

Para Frank essas inferências levam a uma má compreensão do direito. A imprevisibilidade seria causada, ao contrário, pelo $\mathrm{F}$ da equação. A incerteza está no fato de que não possível assegurar que a corte será capaz de encontrar o $\mathrm{F}$ que seja realmente e objetivamente correspondente aos fatos ocorridos, garantindo, com isso, justiça em parâmetro absoluto, pois, como visto, o direito trabalha com verossimilhança e não 
verdade. Assim, não importa quão seguras as leis sejam, as decisões ainda estarão a mercê das dificuldades de se determinar os fatos (FRANK, 1973, p. 15).

O F para o processo é, na melhor das hipóteses, o que o juiz pensa que aconteceu. Pode ser, no entanto, que essa percepção esteja invariavelmente incorreta. A visão metafísica do direito concentra os esforços no $\mathrm{R}$, a regra de direito, enquanto o produto do direito, a concretização dos preceitos através da decisão judicial, depende tanto da regra quanto do $\mathrm{F}$, os fatos. Assim, a discussão dos fatos se dá dentro de parâmetros retóricos que são relativos e incertos. Não há que se falar em verdade como última palavra ou conceito absoluto de justiça na discussão dos fatos no procedimento judicial. A decisão judicial é limitada pelas contingências que a metafísica não pode admitir.

Com isso, tem-se da análise da produção da decisão judicial que esta se dá em parâmetros retóricos contingentes, ao contrário do que defende Rawls. Não se pode defender, nos termos retóricos e realistas, ciência do direito metafísica ou justiça de maneira absoluta e dedutível por todos, pois o direito parte da dúvida e trabalha com pressupostos razoáveis.

\section{Considerações finais}

Rawls desenvolve a teoria da justiça por equidade fundada em preceitos metafísicos, em que verdade e justiça podem serabsolutos e dedutíveis por todos. No entanto, a racionalidade do procedimento judicial é retórica e por isso relativa e contingente; nega, por natureza, a metafísica. O realismo jurídico ajuda a demonstrar onde está a subjetividade e o espaço da retórica na discussão judicial.

Com isso, tem-se que a racionalidade universal de Rawls se dá em parâmetros metafísicos que não podem ser observados no procedimento judicial. Pelo contrário, a decisão e a própria legislação são produtos da racionalidade retórica contingente e relativa, essencialmente tópica.

Da mesma maneira, a cidadania em Rawls, a medida que depende da concretização dos princípios de justiça absolutos colocados em prática pelas instituições sociais, fica prejudicada. A cidadania não pode depender de conceitos metafísicos de justiça. A cidadania, como a própria verdade judicial, é 
construção retórica contingente que muda e se molda a partir dos problemas casuísticos, não parte do sistema em si, como qualquer outro problema retórico.

Dessa forma,a pergunta inicial do trabalho sobre se os parâmetrosde justiça de Rawls podem sobreviver à analise do procedimento do judiciário para garantir a justiça foi respondida afirmando a hipótese de que não, a racionalidade processual é retórica e por isso contingente, depende de escolhas e preferências que a metafisica não é capaz de admitir.

\section{Referências}

ARISTÓTELES. Retórica. Tradução de Manuel Alexandre Júnior, Paulo Farmhouse Alberto e Abel do Nascimento Pena. Lisboa: Imprensa Nacional - Casa da Moeda, 2005.

. Tópicos. Trad. Levi Condinho. Lisboa: Imprensa Nacional - Casa da Moeda, 2007.

FRANK, Jerome. Courts on trial: myth and reality in american justice. Princenton: PrincentonUniversity Press, 1973.

Derecho e incertidumbre. Buenos Aires: Centro Editor da America Latina, 1968.

FREUD, Sigmund. A psicanálise e a determinação dos fatos nos processos jurídicos. In: Obras completas de Sigmund Freud vol. IX. Rio de Janeiro: Imago Editora, 1976.

HOLMES, Oliver Wendell Jr. The path of the law [ebook].Project Gutenberg. Disponível em http://www.gutenberg.org/files/2373/2373-h/2373-h.htm. 2006.

KANT, Immanuel. Fundamentación para una metafísica de lascostumbres. Trad. Roberto Aramayo. Madrid: Alianza editorial, 2008.

KENNEDY, Duncan. In: LeftLegalism. BROWN, Wendy; HALLEY, Janet (Org.). La critica de losderechos em losCritical Legal Sudies. Trad. Juan Bertomeu. NC: Duke University Press, 2002. P. 47-90.

MEDEIROS, Morton Luiz Faria de A. A retórica e a reconstituição da "verdade" na decisão jurídica. Revista Direito e Liberdade, Natal, v.17, n. 2, p. 125-143, maio-agosto. 2015. Quadrimestral. 
NUSSBAUM, Martha. Fronteiras da justiça. Trad. Susana de Castro. São Paulo: Martins Fontes, 2013.

OLIVEIRA, Neiva Afonso. Rousseu e Rawls: contrato em duas vias. Porto Alegre: EDIPUCRS, 2000.

PERELMAN, Chaim. O Império Retórico. Trad.Fernando Trindade e Rui Alexandre Grácio. Lisboa: Asa, 1993.

RAWLS, John. Justiça como equidade: uma reformulação. Trad. Claudia Berliner. São Paulo: Martins Fontes, 2003.

. Uma teoria da justiça. Trad. VamirehChacon.

Brasília: Ed. Universidade de Brasília, 1981.

SORTO, Fredys Orlando; MAIA, Mario Sergio Falcão. In: LEAL, Mônia Clarissa Henning (Org.). Trabalho, constituição e cidadania: reflexões acerca do papel do constitucionalismo na ordem democrática. Porto Alegre: Verbo Jurídico, 2009. P.97108.

VIEHWEG, Theodor. Tópica e Jurisprudência. Brasilia: Universidade de Brasilia, 1979. 